\title{
A20 undermines alternative NF-KB activity and expression of anti-apoptotic genes in Helicobacter pylori infection
}

\author{
Michelle C. C. Lim ${ }^{1}$ - Gunter Maubach ${ }^{1}$ - Anna M. Birkl-Toeglhofer ${ }^{2} \cdot$ Johannes Haybaeck $^{2} \cdot$ Michael Vieth $^{3}$. \\ Mchael Naumann ${ }^{1}$ (i)
}

Received: 10 September 2021 / Revised: 16 December 2021 / Accepted: 8 January 2022 / Published online: 28 January 2022

(c) The Author(s) 2022

\begin{abstract}
A hallmark of infection by the pathogen Helicobacter pylori, which colonizes the human gastric epithelium, is the simultaneous activation of the classical and alternative nuclear factor kappa-light-chain-enhancer of activated B cells (NF- $\mathrm{kB}$ ) pathways, underlying inflammation and cell survival. Here, we report that the classical NF- $\mathrm{KB}$ target gene product A20 contributes to the negative regulation of alternative NF- $\mathrm{KB}$ signaling in gastric epithelial cells infected by $H$. pylori. Mechanistically, the de novo synthesized A20 protein interacts with tumor necrosis factor receptor-associated factor-interacting protein with forkhead-associated domain (TIFA) and thereby interferes with the association of TIFA with the NIK regulatory complex. We also show that alternative NF- $\mathrm{KB}$ activity contributes to the up-regulation of anti-apoptotic genes, such as baculoviral IAP repeat containing 2 (BIRC2), BIRC3 and B-cell lymphoma 2-related protein A1 (BCL2A1) in gastric epithelial cells. Furthermore, the observed over-expression of RelB in human gastric biopsies with type B gastritis and RelB-dependent suppression of apoptotic cell death emphasize an important role of the alternative NF- $\mathrm{kB}$ pathway in $\mathrm{H}$. pylori infection.
\end{abstract}

Keywords ADP-heptose $\cdot$ TIFA $\cdot$ LT $\alpha_{1} \beta_{2} \cdot$ NIK $\cdot$ p100 $\cdot$ RelB

\section{Background}

The human pathogen Helicobacter pylori is a Gram-negative bacterium which colonizes the gastric mucosal epithelium. Infection with $H$. pylori is common with a worldwide prevalence of $44 \%$ [1]. Unless treated, infection by $H$. pylori is persistent leading to chronic active gastritis. In addition, infection with $H$. pylori constitutes a major risk factor for the development of gastric neoplasia [2]. Importantly, the activation of NF- $\mathrm{\kappa B}$ by $\mathrm{H}$. pylori infection is the key contribution to the pro-inflammatory response and cell survival in the gastric mucosa [3].

Mchael Naumann

Naumann@med.ovgu.de

1 Institute of Experimental Internal Medicine, Otto Von Guericke University, Magdeburg, Germany

2 Institute of Pathology, Neuropathology and Molecular Pathology, Medical University of Innsbruck, Innsbruck, Austria

3 Institute of Pathology, Friedrich-Alexander University Erlangen-Nuremberg, Klinikum Bayreuth, Bayreuth, Germany
In general, two branches of NF- $\mathrm{kB}$ activating pathways have been described: the classical and the alternative. The classical NF- $\mathrm{KB}$ pathway can be activated by a variety of stimuli, such as the pro-inflammatory cytokines interleukin- $1 \beta$ or tumor necrosis factor (TNF) and microbial pathogen-derived molecules [4]. The primary mechanism for classical NF- $\kappa \mathrm{B}$ activation is the inducible IкB kinase complex (IKK)-mediated phosphorylation and thereafter degradation of I $\kappa \mathrm{B} \alpha$. Consequently, the released classical NF- $\kappa \mathrm{B}$ heterodimers, predominantly RelA/p50, translocate to the nucleus and regulate the expression of target genes including anti-apoptotic genes [5]. Notably, microbial pathogens have developed strategies to circumvent the NF- $\mathrm{\kappa B}$ activity, underscoring the importance of the NF- $\mathrm{KB}$ pathway as a defense mechanism [6]. Activation of the alternative NF- $\kappa B$ pathway occurs upon stimulation of a subset of receptors belonging to the TNF receptor superfamily by their cognate ligands. These receptors include lymphotoxin $\beta$ receptor (LT $\beta R$ ), fibroblast growth factor-inducible 14 (Fn14), receptor activator of NF- $\mathrm{KB}$ (RANK), cluster of differentiation 40 (CD40) and B-cell-activating factor receptor (BAFF-R) [7]. The NF- $\kappa B$-inducing kinase (NIK) is the key signaling component that activates the alternative NF- $\kappa \mathrm{B}$ pathway. 


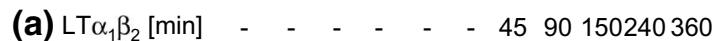

Hp [min] - 4590150240360 - - - - -

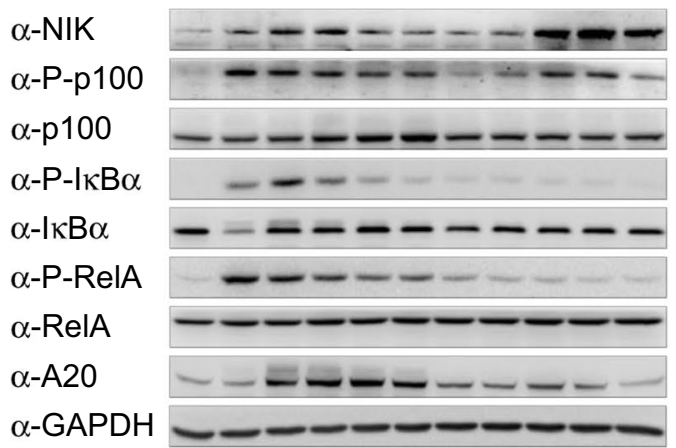

(c)

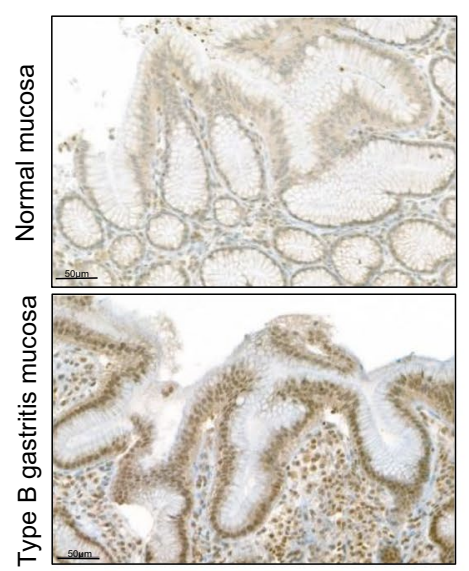

(e)

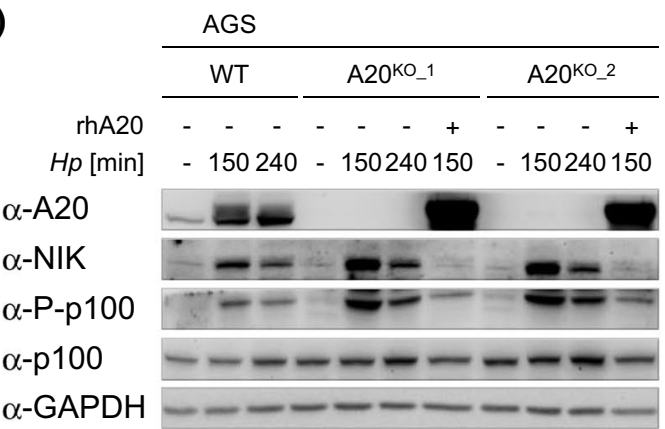

(g)

\begin{tabular}{|c|c|c|c|}
\hline & \multicolumn{3}{|l|}{ AOS } \\
\hline & WT & A20 KO_1 & $\mathrm{A} 2 \mathrm{O}^{\mathrm{KO}} \_2$ \\
\hline $\mathrm{LT}_{\alpha_{1} \beta_{2}}$ [min] & -150240 & -150240 & -150240 \\
\hline$\alpha-A 20$ & --- & & \\
\hline$\alpha-\mathrm{NIK}$ & -- & $1=-$ & \\
\hline$\alpha-P-p 100$ & $\therefore=$ & $=$ & - \\
\hline$\alpha-p 100$ & --- & --- & --- \\
\hline$\alpha-G A P D H$ & $-\cdots-$ & --- & --- \\
\hline
\end{tabular}

(b)

\begin{tabular}{|c|c|}
\hline$H p$ [min] & - 150240 \\
\hline$\alpha-p 52$ & $-1-$ \\
\hline$\alpha$-RelB & $-=-$ \\
\hline$\alpha-G A P D H$ & $-1-$ \\
\hline$\alpha-p 52$ & -1 \\
\hline$\alpha$-RelB & -- \\
\hline$\alpha-H D A C 1$ & --- \\
\hline
\end{tabular}

(d) Cytoplasmic RelB

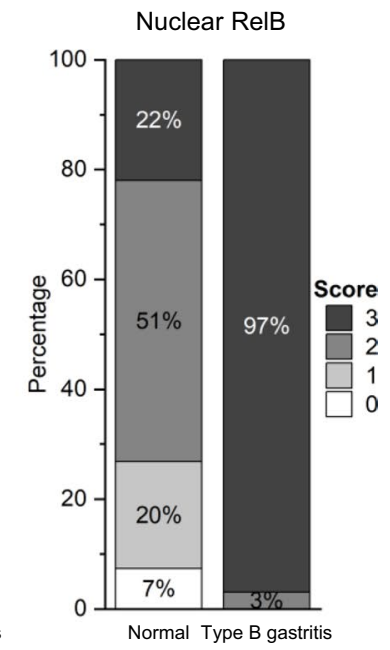

(f)

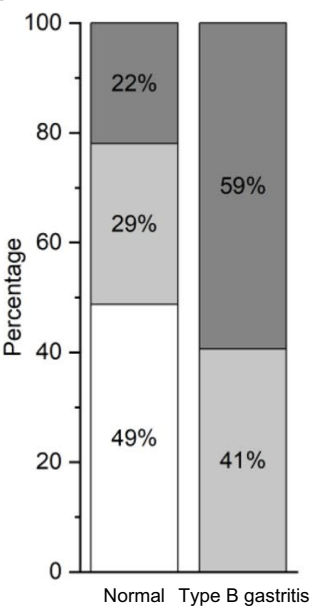

\begin{tabular}{|c|c|c|}
\hline \multicolumn{3}{|l|}{ AGS } \\
\hline WT & A20 KO_1 & A20 $\mathrm{KO}_{2} 2$ \\
\hline - 15024 & - 150240 & -15024 \\
\hline
\end{tabular}

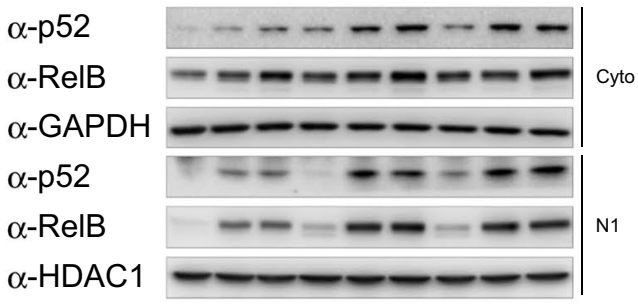


4Fig. 1 A20 participates in the negative regulation of alternative NF- $\mathrm{KB}$ activation in $H$. pylori infection. a AGS cells were infected with $H$. pylori or stimulated with $30 \mathrm{ng} / \mathrm{ml} \mathrm{LT} \alpha_{1} \beta_{2}$. Total cell lysates were analyzed for the indicated proteins by immunoblot (IB). b AGS cells were infected with $H$. pylori. The cytosolic (Cyto) and soluble nuclear (N1) fractions were analyzed by IB. c Representative immunohistochemical micrographs of RelB-stained normal (upper panel) or type B gastritis (lower panel) gastric mucosal specimens. See scale bar for magnification. d Left graph shows moderate cytoplasmic RelB staining intensity in type B gastritis cases, while weaker staining intensity was observed in healthy control gastric specimens, $p<0.001$. Right graph shows high nuclear RelB staining intensity in the case of type B gastritis $(n=32)$ compared to normal gastric mucosa $(n=41), p<0.001$. e Wild-type AGS (WT) and two clones of A20-deficient AGS cells (A20 ${ }^{\mathrm{KO}} \_1$ and $\mathrm{A} 20^{\mathrm{KO} \_} 2$ ) were infected with $H$. pylori. Total cell lysates were analyzed for the indicated proteins by IB. f WT, A20 ${ }^{\mathrm{KO} \_1}$ and A20 ${ }^{\mathrm{KO} \_2}$ AGS cells were infected with H. pylori. The cytosolic (Cyto) and soluble nuclear (N1) fractions were analyzed by IB. g WT, A20 ${ }^{\mathrm{KO}} \_1$ and $\mathrm{A} 20^{\mathrm{KO}}{ }^{2}$ AGS cells were treated with $30 \mathrm{ng} / \mathrm{ml} \mathrm{LT} \alpha_{1} \beta_{2}$. Total cell lysates were analyzed for the indicated proteins by IB. A representative blot of at least two experiments was shown

In the cytosol of resting cells, the level of NIK is barely detectable due to its interaction with the NIK regulatory complex consisting of TRAF3, TRAF2 and cIAP1 or cIAP2 (cIAP1/2) [8]. Specifically, the interaction of TRAF3 with TRAF2 enables the TRAF2-bound cIAP1/2 to catalyze the ligation of K48-linked polyubiquitin to TRAF3-bound NIK, ensuring the constant degradation of NIK by the $26 \mathrm{~S}$ proteasome. Activation of an appropriate receptor leads to the recruitment of the NIK regulatory complex to the cytoplasmic region of the receptor. Depending on the stimulus, separate mechanisms are involved that lead to the disruption of the NIK regulatory complex; as a result, NIK is released and accumulates in the cytosol $[7,9,10]$. Stabilized NIK activates IKK $\alpha$ by phosphorylation and both proteins bind to the RelB/p100 dimer [11]. Next, IKK $\alpha$ phosphorylates p100, leading to its proteolytic processing to $\mathrm{p} 52$ and the subsequent nuclear translocation of the RelB/p52 heterodimer [7]. In addition, classical NF- $\mathrm{\kappa B}$ regulates the transcription of RelB [12] and p100 [13], and promotes the generation of more RelB/p52 dimers.

H. pylori induces classical NF- $\mathrm{KB}$ in human gastric epithelial cells in a type IV secretion system (T4SS)-dependent and cytotoxin-associated gene A (CagA)-independent manner $[14,15]$. Recently, the ADP-L-glycero- $\beta$-D-mannoheptose (ADP-heptose) of Gram-negative bacteria, a metabolic precursor of lipopolysaccharide, has been identified as the predominant trigger of the classical NF- $\mathrm{\kappa B}$ pathway via binding to the cytosolic alpha-protein kinase 1 (ALPK1) [16]. The catalytic activity of ALPK1 is required for the selfoligomerization of tumor necrosis factor receptor-associated factor (TRAF)-interacting protein with forkhead-associated domain (TIFA) [17], which together with TRAF6 and transforming growth factor $\beta$-activated kinase 1 (TAK1) activates the classical NF- $\mathrm{KB}$ pathway [18]. The ADP-heptose
- ALPK1 - TIFA signaling module is also essential for alternative NF- $\mathrm{KB}$ activation by $H$. pylori. We have recently shown that the binding of TIFA to the NIK regulatory complex facilitates the proteasome-dependent transient turnover of cIAP1, resulting in the stabilization of NIK [18].

An important target gene of the classical NF- $\mathrm{\kappa B}$ is TNFAIP3 which encodes A20. The A20 protein contains an $\mathrm{N}$-terminal ovarian tumor domain, which has a deubiquitinylase activity, and $\mathrm{C}$-terminal zinc finger $(\mathrm{ZnF})$ domains, of which the $\mathrm{ZnF} 4$ and $\mathrm{ZnF} 7$ domains function as ubiquitinbinding domains [19]. Herein, A20 down-regulates classical NF- $\kappa B$ signaling either in a catalytic or a non-catalytic manner [20-24].

First attempts to infect the gastric epithelium under conditions close to the in vivo situation have been made using 3D organoids and 2D organoid monolayers. These data showed that $H$. pylori infection leads to a reliable induction of NF- $\mathrm{KB}$ signaling and expression of its target genes, comparable to that in gastric cancer cell lines [25-27]. Unlike certain stimuli that induce prominently either the classical or alternative NF-KB pathway, our studies showed that infection by $H$. pylori induces robustly both NF- $\mathrm{KB}$ pathways $[28,29]$. Thus, we took advantage of this phenomenon in H. pylori-infected cells to study the function of classical $\mathrm{NF}-\kappa \mathrm{B}$-induced A20 in the alternative NF- $\mathrm{BB}$ pathway. Taken together, our study establishes that classical NF- $\mathrm{kB}$ dependent up-regulation of A20 suppresses not only classical but also alternative NF- $\mathrm{\kappa B}$, and blocks expression of specific anti-apoptotic genes.

\section{Results}

\section{A20-deficient gastric epithelial cells show enhanced alternative NF-KB activation in $\mathbf{H}$. pylori infection}

In H. pylori-infected AGS cells, we observed an early (within $45 \mathrm{~min}$ ) inducible phosphorylation of I $\mathrm{BB} \alpha$ and RelA, followed by a significant increase in de novo synthesized A20, indicating classical NF- $\mathrm{KB}$ activation (Fig. 1a). Concomitantly, we also observed the activation of alternative NF- $\mathrm{KB}$ as shown by the transient accumulation of NIK (peaked at $2.5 \mathrm{~h}$ ) and the inducible phosphorylation of p100 (Fig. 1a), as well as the nuclear translocation of p52 and RelB, which are the essential dimer-forming subunits of alternative NF- $\kappa B$ (Fig. 1b). In comparison, stimulation by $\mathrm{LT} \alpha_{1} \beta_{2}$ led to a slower and longer kinetic of alternative NF- $\kappa \mathrm{B}$ activation (Fig. 1a). Contrary to infection by H. pylori, $\mathrm{LT} \alpha_{1} \beta_{2}$ treatment triggered negligible classical NF- $\mathrm{KB}$ signaling, therefore no significant up-regulation in the expression of A20 was observed (Fig. 1a). H. pylori-induced alternative NF- $\mathrm{KB}$ activation was also observed in the epithelial cell lines NCI-N87 and HKC-8 (Suppl. Fig. S1a, b). To 
corroborate our in vitro data, we studied RelB expression in human gastric tissue biopsy samples with no pathological changes and samples from patients with $H$. pylori-associated type B gastritis by immunohistochemistry. RelB was evident in both the nuclei and the cytoplasm of epithelial cells in the gastric mucosa (Fig. 1c). RelB staining was mainly observed as nuclear staining in epithelial cells and the tissue intensity score was significantly higher in type B gastritis than in non-H. pylori-infected tissue (Fig. 1d, right graph), indicating enhanced alternative NF- $\mathrm{BB}$ signaling that may be pathologically relevant. Moderate cytoplasmic RelB staining was also seen in type B gastritis cases, whereas weak staining intensities were detected in samples with no pathological changes (Fig. 1d, left graph). These observations could be attributed to the up-regulation of RelB expression by activation of the classical NF- $\kappa \mathrm{B}$ [12].

To explore the role of A20 in the alternative NF- $\mathrm{BB}$ activation induced by $H$. pylori, we used A20-deficient AGS cells generated by CRISPR/Cas9, which are henceforth referred to as $\mathrm{A} 20^{\mathrm{KO}}$ cells. Control AGS cells are referred to as wild-type cells. In A20 ${ }^{\mathrm{KO}}$ cells infected with $H$. pylori strain P1, we observed augmented alternative NF- $\kappa$ B activation as reflected by the significantly increased accumulation of NIK, phosphorylation of p100 as well as nuclear translocation of p52 and RelB (Fig. 1e, f). This observed difference in the activation of alternative NF- $\kappa \mathrm{B}$ in wildtype and $\mathrm{A} 20^{\mathrm{KO}}$ cells was corroborated by infection with another $H$. pylori strain P12 (Suppl. Fig. S2a). Importantly, A $20^{\mathrm{KO}}$ cells complemented by transfection of recombinant human A20 protein showed almost a complete abrogation of alternative NF- $\kappa \mathrm{B}$ activation (Fig. 1e). Similarly, AGS and NCI-N87 cells depleted of A20 by siRNA transfection showed also markedly stronger alternative NF- $\kappa$ B activation (Suppl. Fig. S2b, c). On the contrary, $L T \alpha_{1} \beta_{2}$-induced alternative $\mathrm{NF}-\kappa \mathrm{B}$ activation was significantly reduced in A $20^{\mathrm{KO}}$ cells compared to wild-type cells (Fig. 1g), an observation that is in agreement with the report by Yamaguchi and colleagues [30]. Taken together, our results indicate that in $H$. pylori infection, A20 contributes to the abatement of alternative NF- $\kappa \mathrm{B}$ signaling, resulting in less RelB/p52 in the nucleus.

\section{A20 interacts with NIK regulatory complex-bound TIFA in H. pylori infection}

We have recently shown that TIFA is crucial for $H$. pyloriinduced alternative NF- $\kappa \mathrm{B}$ activation. Specifically, the binding of TIFA to the NIK regulatory complex (TRAF3/ TRAF2/cIAP1) supports the proteasome-dependent transient turnover of cIAP1 and the ensuing accumulation of NIK [18]. Thus, we asked whether A20 functions at this juncture in the alternative NF- $\mathrm{NB}$ signaling pathway. Intriguingly, in a TRAF2 IP, we found at early time points after
H. pylori infection a stronger and longer lasting association of TIFA with TRAF2 in A20 $0^{\mathrm{KO}}$ cells, which correlated with decreasing amounts of cIAP1 (Fig. 2a). Further, an inducible interaction of TRAF2 and A20 was triggered upon $H$. pylori infection (Fig. 2a, b) but not in response to $\mathrm{LT} \alpha_{1} \beta_{2}$ treatment (Fig. 2b). In TIFA-knockout cells, no A20 was co-immunoprecipitated with TRAF2 (Fig. 2b). These observations are consistent with our previous findings that the association of TIFA with the NIK regulatory complex is specific for $H$. pylori infection [18] and also suggest that the interaction of A20 with the NIK regulatory complex depends on TIFA.

To narrow down the direct interaction partner of A20 in the NIK regulatory complex, we performed siRNA-mediated depletion of TRAF2, cIAP1 or TRAF3 followed by a TIFA IP. Strikingly, knockdown of TRAF2, cIAP1 or TRAF3 did not prevent the binding of A20 to TIFA in response to H. pylori infection (Fig. 2c, Suppl. Fig. S3a). When we incubated recombinant human A20 and TIFA proteins together in vitro, we could immunoprecipitate the A20 protein in a TIFA IP (Fig. 2d) and vice versa (Fig. 2e). These results led us to speculate that this interaction is of relevance to the function of A20 in the suppression of TIFA-dependent alternative NF- $\kappa \mathrm{B}$ activity. To test this hypothesis, we infected A $20^{\mathrm{KO}}$ cells and performed a TIFA IP. Immunoblot analyses of the TIFA-immunoprecipitates revealed the association of components of the NIK regulatory complex with TIFA (Fig. 2f, lanes 2-4). However, when we incubated the IP samples (beads with TIFA-immunoprecipitates) with recombinant human A20 protein for one hour prior to immunoblot analyses of the TIFA-immunoprecipitates, we observed a reduction in the abundance of TIFA-associated cIAP1, TRAF2 and TRAF3 (Fig. 2f, lanes 5-7). Thus, our results demonstrate that upon $H$. pylori infection, A20 binds to TIFA within the NIK regulatory complex that in turn leads to the displacement of TIFA.

\section{Alternative NF-KB signaling promotes the expression of anti-apoptotic genes during $\boldsymbol{H}$. pylori infection}

Classical and alternative NF- $\kappa \mathrm{B}$ signaling regulates distinct as well as overlapping target genes involved in many cellular processes including cell survival [31]. To analyze the impact of $H$. pylori-induced alternative NF- $\mathrm{\kappa B}$ on cell survival, we first carried out quantitative PCR to analyze the transcription of anti-apoptotic genes, BCL2L11 (BIM), $B C L 2$ (BCL2), BIRC2 (cIAP1), BCL2A1 (BCL2A1), CFLAR (cFLIP), BIRC3 (cIAP2) and BIRC5 (survivin), known to be regulated by NF- $\kappa$ B. Infection by $H$. pylori led to a striking albeit transient up-regulation of $B I R C 2$, $B I R C 3$ and BCL2Al (Fig. 3a). In response to H. pylori infection, RelB-depleted cells showed a lower expression of these three genes, suggesting that they are regulated 
a

\begin{tabular}{ll} 
AGS \\
\hline WT \\
\hline
\end{tabular}

$\lg \mathrm{s}$

Hp [min] 300 - 4080150240300 - 4080150240300 IP: TRAF2 $\alpha$-clAP1

$\alpha$-TRAF3

$\alpha$-TIFA

$\alpha-\mathrm{A} 20$

$\alpha$-TRAF2

Lysates

$\alpha$-cIAP1

$\alpha$-TRAF3

$\alpha-$ TIFA

$\alpha-\mathrm{A} 20$

$\alpha$-TRAF2

$\alpha$-GAPDH

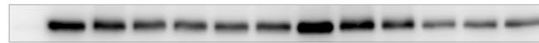

$\begin{array}{llllllllllll}1.00 & 0.70 & 0.54 & 0.53 & 0.64 & 0.65 & 1.00 & 0.72 & 0.51 & 0.41 & 0.48 & 0.65\end{array}$
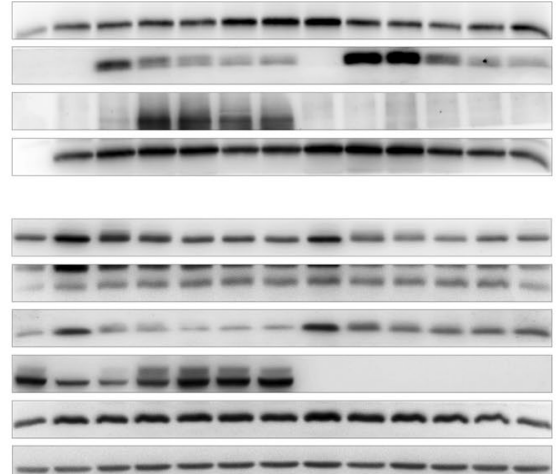

b

\begin{tabular}{l} 
AGS \\
WT \\
\hline
\end{tabular}

$\lg G$

$L T \alpha_{1} \beta_{2}[\mathrm{~min}] \quad-\quad-\quad-\quad-60 \quad-\quad-\quad-60$

$H p$ [min] $30-3060-\quad-3060-$

IP: TRAF2

$\alpha$-clAP1

$\alpha$-TIFA

$\alpha-A 20$

$\alpha$-TRAF2

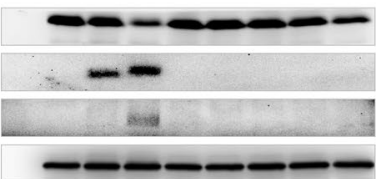

Lysates

$\alpha$-clAP1

$\alpha$-TIFA

$\alpha-\mathrm{A} 20$

$\alpha-$ TRAF2

$\alpha$-GAPDH

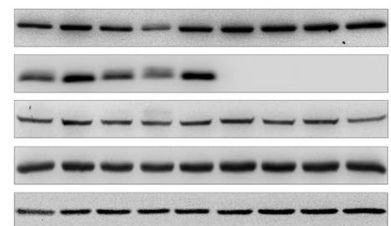

C

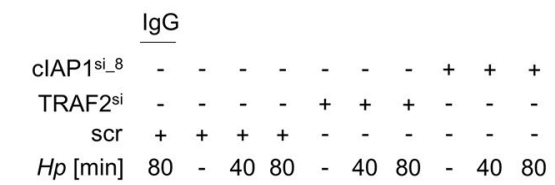

\section{IP: TIFA}

$\alpha$-clAP1

$\alpha$-TRAF2

$\alpha-A 20$

$\alpha$-TIFA

Lysates $\alpha$-clAP1

$\alpha$-TRAF2

$\alpha-A 20$

$\alpha$-TIFA

$\alpha-G A P D H$
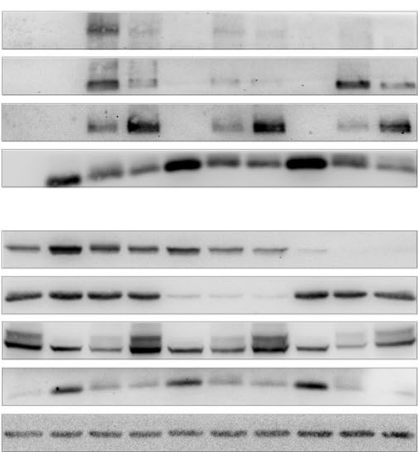

e

d

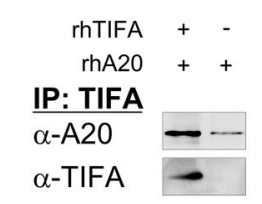

\begin{tabular}{l|l} 
rhTIFA & $\frac{\lg G}{+}+$ \\
rhA20 & ++ \\
IP: A20 & \\
\hline$\alpha-$ TIFA & - \\
$\alpha-A 20$ & -
\end{tabular}

f

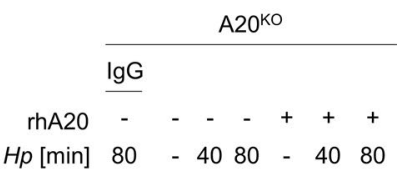

IP: TIFA

$\alpha$-CIAP1

$\alpha$-TRAF2

$\alpha$-TRAF3

$\alpha-\mathrm{A} 20$

$\alpha$-TIFA

Lysates

$\alpha$-clAP1

$\alpha$-TRAF2

$\alpha$-TRAF3

$\alpha$-TIFA

$\alpha-$ GAPDH
Fig. 2 Inhibition of $H$. pylori-mediated alternative NF- $\mathrm{KB}$ signaling pathway by A20 requires TIFA. a WT and A20 ${ }^{\mathrm{KO}-1}$ AGS cells were infected with $H$. pylori. Total cell lysates were harvested and IP was performed using an antibody against TRAF2 or isotype-matched $\operatorname{IgG}(\operatorname{IgG})$. The numbers indicate the band intensities of cIAP1 (normalized to the respective band intensities of TRAF2) of $H$. pyloriinfected samples relative to uninfected control. b WT and TIFAknockout (TIFA ${ }^{\mathrm{KO}}$ ) AGS cells were infected with $H$. pylori or treated with $30 \mathrm{ng} / \mathrm{ml} \mathrm{LT} \alpha_{1} \beta_{2}$. Total cell lysates were subjected to IP as in (a). c AGS cells were transfected with non-target-specific siRNA (scr) or siRNAs targeting TRAF2 $\left(\mathrm{TRAF}^{\mathrm{si}}\right)$ or cIAP1 (cIAP1 ${ }^{\text {i__8 }}$ )

at least in part by alternative NF-кB (Fig. 3b). Further, we examined whether the inhibitory effect of A20 on the alternative NF- $\mathrm{KB}$ pathway could have an impact on the expression of these three anti-apoptotic genes. Upon H. pylori infection, the up-regulation of $B I R C 2, B I R C 3$ and $B C L 2 A 1$ was further increased in $\mathrm{A} 20^{\mathrm{KO}}$ cells compared for $48 \mathrm{~h}$ prior to infection with $H$. pylori. Total cell lysates were used for IP with an antibody against TIFA or isotype-matched IgG. d Following incubation of recombinant human A20 and TIFA proteins in vitro, IP was performed using an antibody against TIFA. e as in (d) but IP was performed using an antibody against A20 or isotypematched IgG. f A20 $20^{\mathrm{KO}} \_1$ AGS cells were infected with $H$. pylori and IP was performed as in (c). IB analyses were performed with TIFAimmunoprecipitates without and with one hour incubation with $100 \mathrm{ng}$ recombinant A20 protein prior to elution of immunoprecipitates. A representative blot of at least two experiments was shown

to wild-type cells (Fig. 3b). This is most likely due to the missing inhibitory effect of A20 on not only the alternative but also the classical NF- $\kappa \mathrm{B}$ signaling pathway. Importantly, RelB-depleted $\mathrm{A} 20^{\mathrm{KO}}$ cells (compromised in alternative NF- $\mathrm{KB}$ ) showed attenuated up-regulation of these anti-apoptotic genes compared to $\mathrm{A} 20^{\mathrm{KO}}$ cells (Fig. 3b). 
Fig. 3 A20 inhibits specific alternative NF- $\mathrm{\kappa B}$-regulated anti-apoptotic genes in $H$. pylori infection. a Total RNA was isolated after $H$. pylori infection of AGS cells. Changes in the expression of the indicated transcripts were analyzed by quantitative PCR. b WT and A20 ${ }^{\mathrm{KO}} \_1$ AGS cells were transfected with non-target-specific siRNA (scr) or siRNA targeting RelB (RelB ${ }^{\text {si_E1 }}$ ) for $48 \mathrm{~h}$ prior to infection by $H$. pylori for $3 \mathrm{~h}$. Total RNA was isolated and analyzed as in (a). a and b Data are normalized to the RPL13A housekeeping gene and expressed as fold change in mRNA expression relative to uninfected cells. Triplicate determinations of each experiment was performed. Error bars denote means \pm SD of at least two independent experiments. ${ }^{\#} p<0.05, * p<0.01$ and $* * p<0.001$

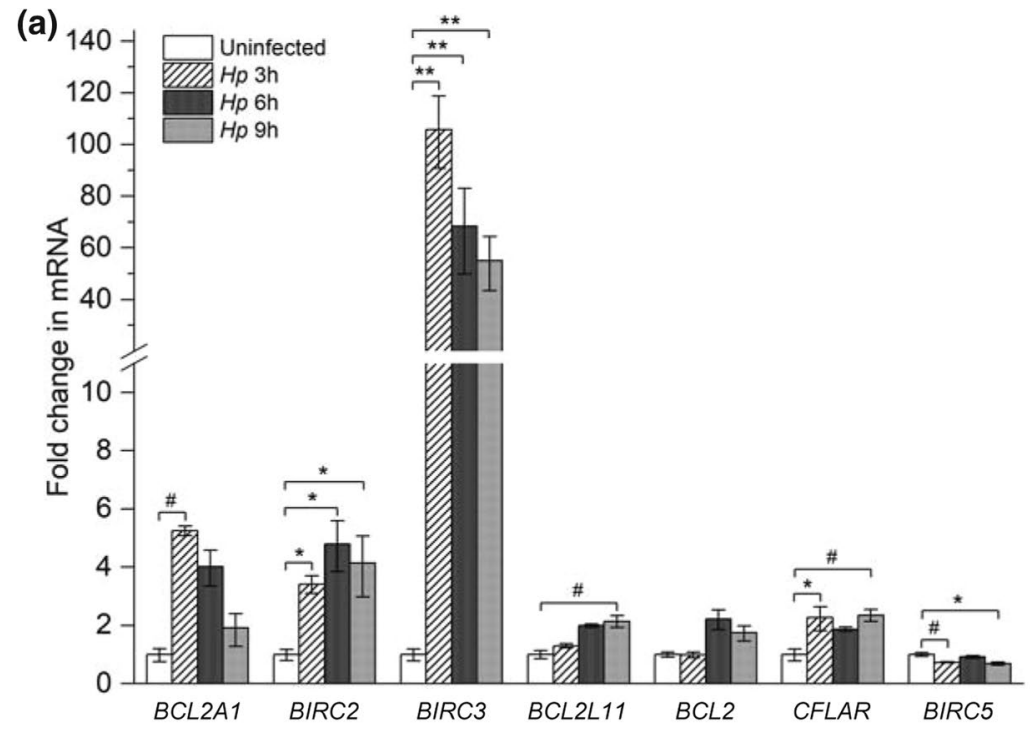

(b)

BIRC2

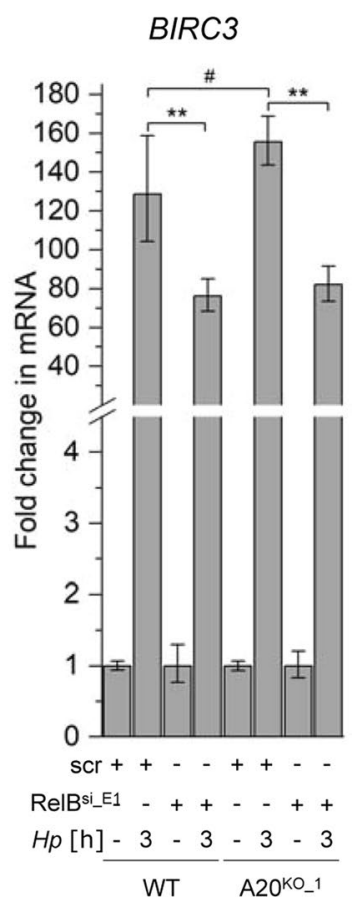

This diminished up-regulation represents the contribution of alternative NF- $\mathrm{KB}$ to the expression of these antiapoptotic genes.

We proceeded to determine apoptotic cell death by flow cytometric analysis of cells stained with annexin V-FITC and propidium iodide (PI). After H. pylori infection, we observed an increase in the percentage of apoptotic cells in control and RelB-depleted cells compared to their uninfected counterparts, 9.6 to $20.2 \%$ and 14.4 to $27.0 \%$, respectively (Fig. 4a), indicating that cells with reduced expression of RelB were even more sensitive to $H$. pylori-induced apoptosis. Taken together, our data imply that A20 undermines cell survival to a certain extent because of its inhibitory effect on alternative and classical NF- $\mathrm{kB}$-dependent regulation of anti-apoptotic genes.

\section{Discussion}

Infection by $H$. pylori, which mediates in parallel prominent activation of the classical as well as the alternative NF- $\mathrm{KB}$ signaling pathways, provides us with a unique opportunity to examine the impact of $\mathrm{A} 20$, a classical NF- $\mathrm{KB}$-induced gene product, on the regulation of the alternative NF- $\mathrm{KB}$ pathway. In this study, we demonstrate that $\mathrm{A} 20$ participates in the negative regulation of alternative NF- $\mathrm{KB}$ signaling and gene 
(a)

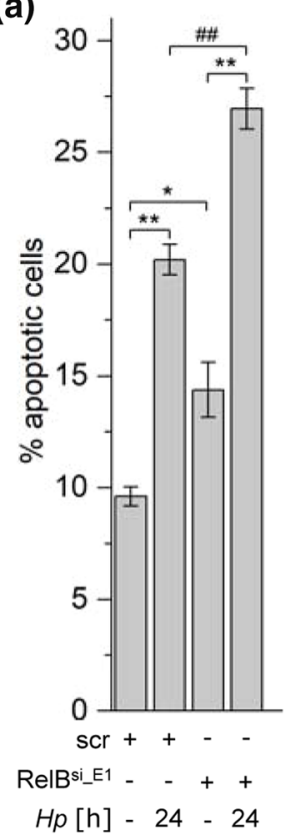

$\mathrm{scr}$

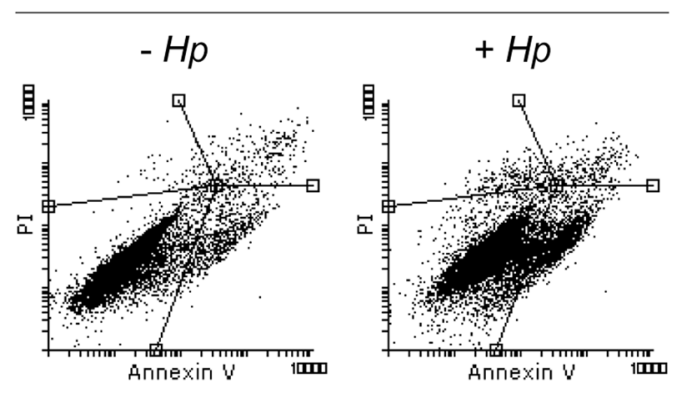

RelBsi_E1

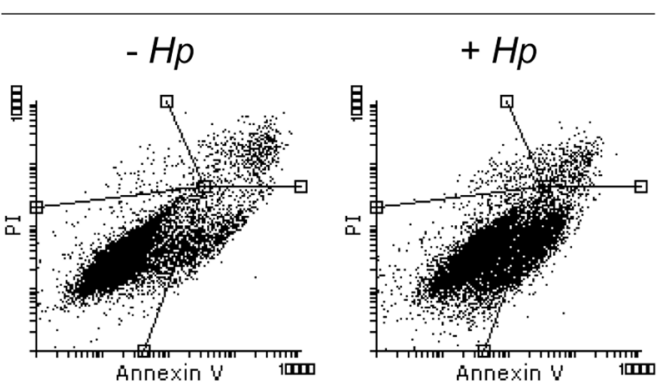

(b)
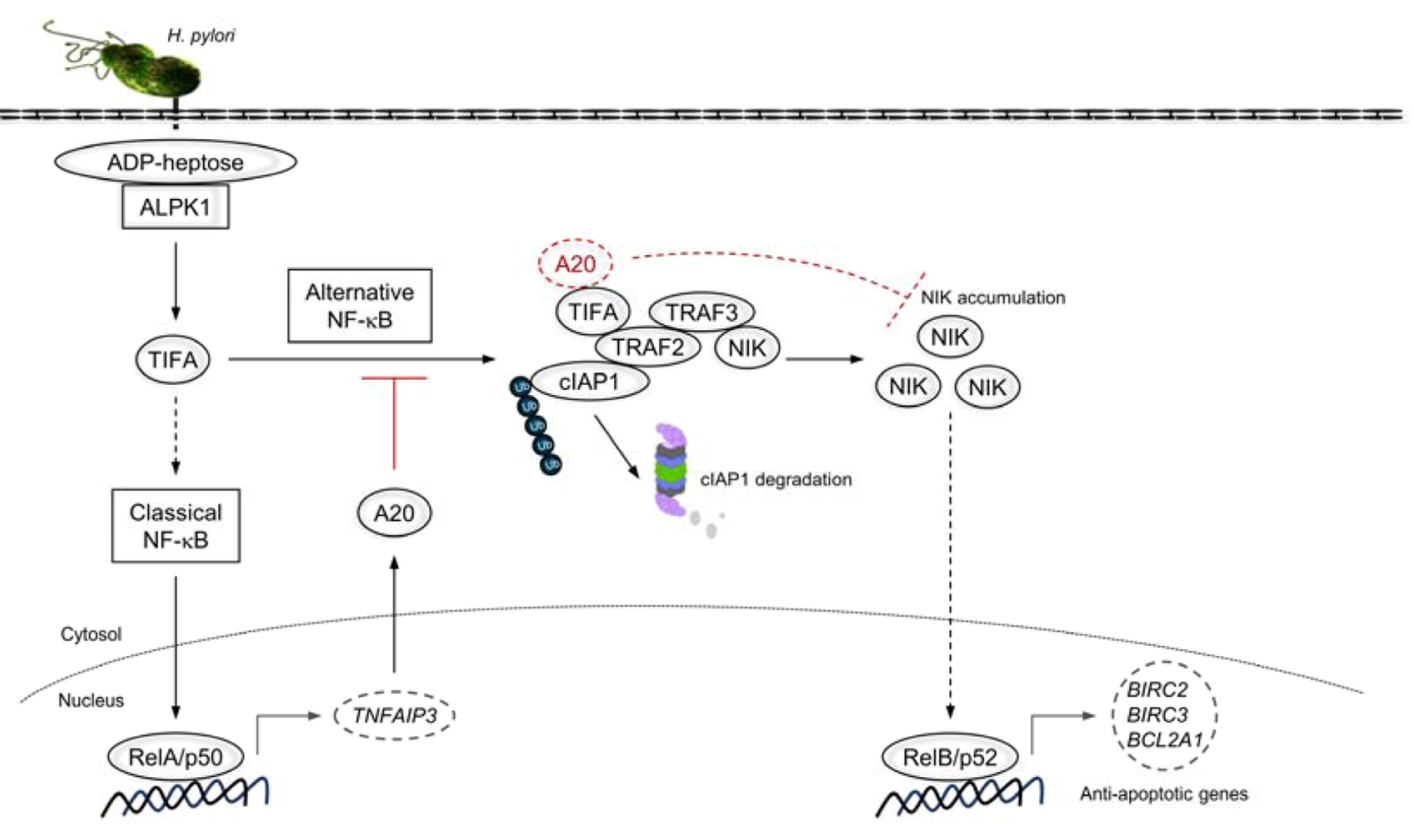

Fig. 4 Alternative NF- $\kappa \mathrm{B}$ signaling contributes to cell survival in H. pylori infection. a AGS cells were transfected with non-targetspecific siRNA (scr) or siRNA targeting RelB (RelB ${ }^{\text {si_E1 }}$ ) for $48 \mathrm{~h}$. After $H$. pylori infection for $24 \mathrm{~h}$, cells were harvested and stained with annexin V-FITC/PI, and analyzed by flow cytometry. A graph showing data from three independent experiments is depicted (means $\pm \mathrm{SD}$ ). ${ }^{\# \#} p<0.005, * p<0.01$ and $* * p<0.001$. Representative dot plots are shown for each treatment. b A proposed model for A20's role in the negative regulation of alternative NF- $\mathrm{KB}$ signaling pathway in $H$. pylori infection. $H$. pylori-induced activation of the classical NF- $\kappa \mathrm{B}$ pathway results in the up-regulation of A20 expression. A20 binds to TIFA in the TIFA/NIK regulatory complex, which in turn destabilizes the association of TIFA with the complex. This restores the stability of cIAP1 in the complex and this TIFA-free NIK regulatory complex recovers the ability to mediate the proteasomal degradation of NIK, leading to the shutdown of alternative NF- $\mathrm{BB}$ signaling 
regulation during $H$. pylori infection (Fig. 4b). Accordingly, A20 interacts with TIFA within the TIFA/NIK regulatory complex, which in turn destabilizes the interaction of TIFA with the complex. This restores the stability of cIAP1 in the complex, an observation that is consistent with our previous findings [18]. This TIFA-free NIK regulatory complex recovers the ability to mediate the proteasomal degradation of NIK, leading to the shutdown of alternative NF- $\mathrm{\kappa B}$ signaling.

In a previous publication [29], we have established by knockdown experiments that the LT $\beta \mathrm{R}$ is involved in H. pylori-induced alternative NF- $\mathrm{\kappa B}$. However, the role of the LT $\beta R$ in contributing to the activation of the alternative NF- $\mathrm{KB}$ is not clear. Here, an internalization of the LT $\beta R$ as described by Ganeff et al. [32] could be a way where the receptor is involved independent of its ligand. The cytoplasmic binding of TRAF2/3 to the internalized LT $\beta$ R might contribute to the liberation of NIK from the NIK regulatory complex [9] after cIAP1 is unable to further ubiquitinylate NIK [18]. Further, an earlier study reported that A20 was involved, independent of its catalytic activities, in the activation of LT $\beta R$, Fn14, and RANK-mediated alternative NF- $\kappa B$ signaling in mouse embryonic fibroblasts and MDA-MB-231 cells [30]. These authors reported that in ligand-receptor-mediated activation of alternative NF- $\mathrm{\kappa B}$, the binding of A20 to cIAP1 results in the disruption of the interaction between TRAF2 and TRAF3. This in principle leads to the disintegration of the NIK regulatory complex so that NIK could accumulate and activate alternative NF- $\kappa B$ signaling. In the course of this study and our previous observations [18], we showed that involvement of the ADP-heptose - ALPK1 - TIFA signaling module is the feature that distinguishes the activation of alternative NF- $\mathrm{KB}$ in $H$. pylori infection from ligand-receptor-mediated signaling. Consistently, we show in the current study that A20 requires TIFA to fulfill its inhibitory function on $\mathrm{H}$. pylori-induced alternative NF- $\mathrm{kB}$ signaling. Therefore, the $H$. pylori-dependent binding of TIFA to the NIK regulatory complex might mask the binding site of A20 on cIAP1, which in turn drives the response of NF- $\mathrm{KB}$-induced A20 toward a different binding partner, and this also explains the distinct functions of A20 reported here and by Yamaguchi et al. [30].

Most knowledge about the alternative NF- $\kappa \mathrm{B}$ pathway has been garnered in connection with lymphoid organogenesis and functions of immune cells, such as B cells and dendritic cells [33]. However, receptors which trigger alternative NF- $\kappa B$ activation including LT $\beta R$, Fn 14 and RANK are also expressed in non-immune cells, such as fibroblasts, endothelial and epithelial cells [34-36]. Whether the alternative NF- $\mathrm{KB}$ signaling in non-immune cells has a function in cell survival has not been investigated in detail. We showed that alternative NF- $\mathrm{KB}$ activity contributes to the up-regulation of survival genes BIRC2, BIRC 3 and $B C L 2 A I$ in epithelial cells. Furthermore, we found a positive correlation between the absence of RelB and the increase in apoptotic epithelial cells upon $H$. pylori infection, suggesting that alternative NF- $\kappa B$ activity is pro-survival. This represents in the pathophysiology of $H$. pylori infection an obvious advantage for the colonizing pathogen to prevent excessive disruption of the integrity of the epithelial barrier. Supporting this notion is an earlier study showing that LT $\beta$ R-driven alternative NF- $\mathrm{KB}$ signaling has a protective role in intestinal epithelial cells by inducing the production of IL-23 to promote cell survival [37]. Our study, therefore, expands the understanding of the impact of alternative NF- $\mathrm{\kappa B}$ activity on cell survival during the colonization of gastric epithelial cells by $H$. pylori. Further investigation is warranted to address comprehensively the cross-talk between this prosurvival function of $H$. pylori-induced alternative NF- $\mathrm{kB}$ and its other function in facilitating the recruitment of immune cells during infection [38].

On the one hand, we have previously reported that A20 interacts with caspase- 8 and suppresses the processing of caspase- 8 , thereby counteracting $H$. pylori-associated caspase-8-dependent apoptotic cell death [39]. On the other hand, we showed in this study that A20 suppresses classical and alternative NF-кB-regulated anti-apoptotic genes, and thereby promotes $H$. pylori-associated apoptotic cell death. The apoptosis response in host cells is a double-edged sword for $H$. pylori because while the bacterium benefits from the nutrients that are provided by the apoptotic host cells, disintegration of the host cells also diminishes its colonization niche. Future studies that focus on elucidating how these opposing functions of A20 are regulated (spatially, temporally and possible involvement of other participating molecules) could reveal ways to better appraise the benefits for H. pylori and broaden our understanding on how these might contribute to cellular transformation and gastric cancer.

\section{Materials and methods}

\section{Cell culture conditions}

AGS (ATCC® CRL-1739'M), NCI-N87 (ATCC® CRL5822 ${ }^{\mathrm{TM}}$ ), HKC-8 (RRID:CVCL_Y910), A20- and TIFAknockout [18] cells were routinely cultivated in RPMI-1640 medium (Gibco $\left.{ }^{\mathrm{TM}}, 21875-034\right)$ supplemented with $10 \%$ fetal calf serum (FCS) at $37^{\circ} \mathrm{C}$ in a $5 \% \mathrm{CO}_{2}$ humidified incubator. Cells were seeded at a density of $6 \times 10^{5}$ per $60 \mathrm{~mm}$ culture dish or $2.7 \times 10^{6}$ per $100 \mathrm{~mm}$ culture dish for infection with $H$. pylori or treatment with recombinant human $\mathrm{LT} \alpha_{1} \beta_{2}$ (R\&D Systems, 8884-LY). Cell culture medium was changed to fresh RPMI-1640 medium supplemented with $0.2 \%$ FCS $16-20 \mathrm{~h}$ prior to infection or treatment of the cells. 


\section{Bacterial culture}

The H. pylori wild-type P1 or P12 (used for Suppl. Fig. S2a only) strain was streaked from $-80^{\circ} \mathrm{C}$ stock onto agar-plates containing $10 \%$ horse serum and $10 \mu \mathrm{g} / \mathrm{ml}$ vancomycin, and cultivated under microaerophilic conditions for $48-72 \mathrm{~h}$. Bacteria was re-plated and cultivated for $48 \mathrm{~h}$ before use in experiments. The bacterial suspension used for infection of cells was prepared in phosphate-buffered saline containing $\mathrm{Mg}^{2+}$ and $\mathrm{Ca}^{2+}$ (PBS). The optical density at $550 \mathrm{~nm}$ was measured to determine the number of bacteria in the suspension. Infection of bacteria was performed at a multiplicity of infection (MOI) 100.

\section{Generation of A20-knockout AGS cell lines using CRISPR/Cas9}

The knockout of A20 in AGS cells was performed using reagents from IDT as described in [18]. The Alt-R® CRISPRCas9 crRNA Hs.Cas9.TNFAIP3.1.AB 5'-AACCATGCA CCGATACACAC TGG -3' (IDT) was used. The control AGS cells used have undergone the same CRISPR/Cas9 procedure but were not successful for the depletion of A20.

\section{Transfection of siRNAs and recombinant proteins}

Transfection of siRNAs was performed using the METAFECTENE® $\mathrm{SI}^{+}$kit (Biontex Laboratories, T100-1.0) according to the manufacturer's protocol. Briefly, $24 \mathrm{~h}$ prior to siRNA transfections, cells were seeded at a density of $1.5 \times 10^{5}$ per $60 \mathrm{~mm}$ culture dish or $0.5 \times 10^{6}$ per $100 \mathrm{~mm}$ culture dish. Cell culture medium was changed to fresh RPMI-1640 supplemented with 10\% FCS prior to transfection. The siRNAs were used at a final concentration of $40 \mathrm{nM}$ for A20, $30 \mathrm{nM}$ for TRAF3, TRAF2 and cIAP1, and $20 \mathrm{nM}$ for RelB. As a control for non-specific effects of the transfection procedure, equimolar of scrambled (non-targetspecific) siRNA was used for the respective experiments. The siRNAs were transfected into the cells for $24 \mathrm{~h}$ before the cell culture medium was changed to fresh RPMI-1640 medium supplemented with $0.2 \%$ FCS or $10 \%$ FCS (for experiments in Fig. 4a) $16-20 \mathrm{~h}$ prior to $\mathrm{H}$. pylori infection. The following siRNAs were used: scrambled siRNA (Qiagen, SI03650318); A20 ${ }^{\text {si_5 }}$ (Dharmacon, J-009919-050005); A20 ${ }^{\text {si_9 }}$ (Qiagen, SI05018601); RelB ${ }^{\text {si_E1 }}$ (Eurofins, 5'-GACUGCACCGACGGCAUCU-dTT-3' [40]); TRAF3 (Santa Cruz Biotechnology, sc-29510); TRAF2 (Santa Cruz Biotechnology, sc-29509); and cIAP1 (Qiagen, SI02654442).

Transfection of recombinant human A20 protein (BPS Bioscience, 80408) was performed using reagents from the Lipofectamine ${ }^{\circledR}$ CRISPRMAX transfection reagent kit (Invitrogen, CMAX00015). Twenty-four hours prior to protein transfection, cells were seeded at a density of $6 \times 10^{5}$ per $60 \mathrm{~mm}$ culture dish. The cell culture medium was changed to fresh RPMI-1640 medium supplemented with $0.2 \%$ FCS prior to transfection. One microgram recombinant protein was combined with $5 \mu \mathrm{l}$ Cas9 PLUS ${ }^{\mathrm{TM}}$ reagent in $500 \mu \mathrm{l}$ Opti-MEM (Gibco $\left.{ }^{\mathrm{TM}}, 31985070\right)$ and incubated at room temperature for $5 \mathrm{~min}$. Six microliters of CRISPRMAX transfection reagent diluted in $500 \mu \mathrm{l}$ Opti-MEM was combined with the diluted Cas9 PLUS ${ }^{\mathrm{TM}}$ reagent/recombinant protein solution and incubated at room temperature for $20 \mathrm{~min}$ before adding drop-wise to the cells in the dishes. After 16-20 h, the cells were infected with $H$. pylori.

\section{SDS-PAGE and immunoblotting}

For preparation of total cell lysates, cells were washed twice in ice-cold PBS and $100 \mu \mathrm{l}$ or $500 \mu \mathrm{l}$ of lysis buffer $(50 \mathrm{mM}$ Tris/ $\mathrm{HCl} \mathrm{pH} 7.5,150 \mathrm{mM} \mathrm{NaCl}, 5 \mathrm{mM}$ EDTA, $10 \mathrm{mM}$ $\mathrm{K}_{2} \mathrm{HPO}_{4}, 10 \%$ glycerol, $1 \%$ Triton X-100 and 0.5\% NP-40) containing phosphatase inhibitors $(1 \mathrm{mM}$ sodium vanadate, $1 \mathrm{mM}$ sodium molybdate, $20 \mathrm{mM}$ sodium fluoride, $10 \mathrm{mM}$ sodium pyrophosphate, $1 \mathrm{mM}$ AEBSF and $20 \mathrm{mM}$ 2-phosphoglycerate) and protease inhibitor mix (Roche Diagnostics, 34044100) was added to a $60 \mathrm{~mm}$ or $100 \mathrm{~mm}$ dish, respectively. Cells were scraped, transferred into microtubes and incubated on ice for $15 \mathrm{~min}$. For preparation of cell lysates for IP, the cell lysates were sheared through a 19G needle several times prior to incubation on ice. Cleared cell lysates were obtained after centrifugation at $13,000 \mathrm{rpm}$ for $15 \mathrm{~min}$ at $4{ }^{\circ} \mathrm{C}$. The subcellular fractionation of cells into cytosolic and soluble nuclear fractions was performed as described in previous work [41].

Protein concentration was determined using the BCA protein assay kit (ThermoFisher Scientific, 23225). SDS-PAGE was performed in Tris-Glycine gels and transferred onto PVDF membranes (Merck Millipore). The membranes were blocked for $1 \mathrm{~h}$ at room temperature using 5\% skim milk in TBS containing $0.1 \%$ Tween (TBS-T). The membranes were incubated overnight with primary antibodies at the appropriate dilutions in either 5\% BSA or 5\% skim milk in TBS-T at $4{ }^{\circ} \mathrm{C}$ on a rocking platform. The membranes were washed thrice in TBS-T and incubated with the appropriate HRPconjugated secondary antibody for $1 \mathrm{~h}$ at room temperature at a dilution of 1:6000 in 5\% skim milk in TBS-T, followed by three washes in TBS-T. The membranes were developed using a chemiluminescent HRP substrate (Merck Millipore, WBKLS0500). The band pattern was visualized using the ChemoCam Imager (Intas).

Antibodies used in this work were as follows: $\alpha$-A20 (5630, used for detection in IB after TRAF2 IP); $\alpha$-cIAP1 (7065); $\alpha$-ІкB $\alpha$ (4812); $\alpha$-NF-кB2 p100/p52 (4882); $\alpha$-NIK (4994); $\alpha$-TIFA $(61,358) ; \alpha$-TRAF3 (61095); $\alpha$-phosphoIкB $\alpha$ (9246); $\alpha$-phospho-p100 (4810); and $\alpha$-phospho-RelA 
(3031) from Cell Signaling Technology; $\alpha$-A20 (sc-166692), $\alpha$-HDAC1 (sc-7872), $\alpha$-RelA (sc-81334), $\alpha$-RelB (sc-226) and $\alpha$-TRAF2 (sc-136999) from Santa Cruz Biotechnology; $\alpha$-TRAF3 (Invitrogen, 700121); and $\alpha$-GAPDH (Merck Millipore, MAB374). The secondary anti-rabbit-HRP (711-036152), anti-mouse-HRP (715-036-151), anti-light chain-specific rabbit-HRP (211-032-171) and anti-light chain-specific mouse-HRP (115-035-174) antibodies were from Jackson ImmunoResearch Laboratories. The anti-light chain-specific secondary antibodies were used for analysis of immunoblots after IPs.

\section{Immunoprecipitation}

Two to four milligrams of total cell lysate was incubated with $1 \mu \mathrm{g}$ antibody against the targeted protein or isotypematched IgG overnight. Protein A/G magnetic beads (ThermoFisher Scientific, 88803) were added followed by incubation for $1 \mathrm{~h}$. Both incubation steps were carried out at $4{ }^{\circ} \mathrm{C}$ on a rotator at $7 \mathrm{rpm}$. The beads with immunoprecipitates were washed three times in lysis buffer and twice in PBS. Elution of immunoprecipitated proteins from the beads was achieved by incubation with $2 \times$ Laemmli sample buffer for $20 \mathrm{~min}$ at room temperature. Eluate was transferred to a clean microtube and heated for $5 \mathrm{~min}$ at $95^{\circ} \mathrm{C}$ prior to SDSPAGE and immunoblotting.

For the experiments in Fig. 2, panels d and e, $50 \mathrm{ng}$ recombinant human A20 and TIFA (Novus Biologicals, NBP1-99103-50ug) proteins, respectively, were combined in $500 \mu \mathrm{PBS}$, and incubated for $1 \mathrm{~h}$. IP was performed by incubation with $1 \mu 1 \alpha$-TIFA or $1 \mu \mathrm{g} \alpha$-A20 (Santa Cruz Biotechnology) antibody for $1 \mathrm{~h}$. Both incubation steps were carried out at $4{ }^{\circ} \mathrm{C}$ on a rotator at $7 \mathrm{rpm}$. Subsequent steps were the same as described in the previous paragraph.

For the experiments in Fig. 2, panel f, after the last washing step of the beads with immunoprecipitates, these were resuspended in $500 \mu \mathrm{l}$ PBS and divided into two aliquots. Elution of immunoprecipitates was performed for one aliquot. One-hundred nanograms recombinant human A20 protein was added to the other aliquot and rotated at $7 \mathrm{rpm}$ for $1 \mathrm{~h}$ at $4{ }^{\circ} \mathrm{C}$. The beads with immunoprecipitates were washed two times in lysis buffer followed by elution of immunoprecipitates.

\section{Flow cytometry}

Analysis of cells after annexin V/propidium iodide (PI) staining was performed using the CyFlow ${ }^{\circledR}$ Space flow cytometer (Sysmex Partec) and quantified using the Flowing Software (version 2.5.1). Cells were harvested using trypsin and stained using the Annexin-V Apoptosis Detection kit (MabTag, AnxF100PI) according to the manufacturer's protocol. A gating for single cells was performed and $1 \times 10^{4}$ cells were counted. For the quantification of cell death, annexin V-positive and double positive (annexin V-plus PI-stained) cells were added together to give the percentage of apoptotic cells.

\section{Quantitative PCR}

Total RNA was isolated using the NucleoSpin ${ }^{\circledR}$ RNA Plus kit (Macherey-Nagel). The total RNA was reverse-transcribed into cDNA using the $\mathrm{RT}^{2}$ HT First Strand kit (Qiagen). Quantitative PCR was performed using the primer sets targeted against BCL2L11, BCL2, BIRC2, BCL2A1, CFLAR, $B I R C 3, B I R C 5$ and RPL13A (endogenous control gene for normalization) provided in the Human Apoptosis Primer Library masterplate (RealTimePrimers, HPA-1). The Comparative $\mathrm{C}_{\mathrm{T}}$ Method $\left(\Delta \Delta \mathrm{C}_{\mathrm{T}}\right)$ was used to quantify relative changes of the target mRNA.

\section{Immunohistochemistry}

Immunohistochemical staining for RelB (1:100 dilution) was performed on paraffin-embedded human gastric tissue sections $(3 \mu \mathrm{m})$ of biopsies (Ethics approval: 347_20 Bc) from H. pylori-negative patients with normal gastric mucosa and H. pylori-positive patients with chronic inflammation using the VENTANA BenchMark XT system and the ultraView Universal DAB detection kit according to the manufacturer's instructions (Ventana Medical Systems). For epitope retrieval, the Benchmark ULTRA CC1 solution ('Mild' heat-induced epitope retrieval standard pre-programmed protocol) was used. Image acquisition was performed with Hamamatsu Nanozoomer S360 scanner and software (Hamamatsu). Staining was evaluated independently by two board-certified pathologists ( $\mathrm{JH}$ and $\mathrm{MV}$ ) and the staining intensity was scored as follows: score 0 was assigned to no staining, score 1 to weak, score 2 to moderate, and score 3 to strong staining according to the Remmele IR score [42].

\section{Densitometric analysis}

The densitometric quantification of cIAP1 band intensities in Fig. 2a was performed using the ImageJ software according to Schneider et al. [43]. For normalization purpose, the values of the cIAP1 band intensities were divided by the values of the respective TRAF2 band intensities. The numbers indicate the normalized band intensities of cIAP1 in H. pylori-infected samples relative to uninfected control.

\section{Statistics}

All quantitative data were analyzed using OriginPro 2020b and are presented as means \pm SD. Time-dependent changes during quantitative PCR studies (Fig. 3a) were tested for 
significance using one-way ANOVA and Bonferroni's post hoc test. All other quantitative data were tested for significance using two-sample Student's $t$ test. $p<0.05$ was regarded as statistical significant. For immunohistochemical analysis, the Mann-Whitney $U$ test was performed (GraphPad 9.0.0). $p<0.001$ was regarded as statistical significant.

Supplementary Information The online version contains supplementary material available at https://doi.org/10.1007/s00018-022-04139-y.

Author contributions MCCL, GM and MN designed the study. MCCL, $\mathrm{GM}, \mathrm{MV}, \mathrm{AMB}$ and $\mathrm{JH}$ conducted the experiments and performed the analysis. MCCL, GM and MN wrote the manuscript. All the authors read and approved the final manuscript.

Funding Open Access funding enabled and organized by Projekt DEAL. This work was supported by grants of the Deutsche Forschungsgemeinschaft (DFG, German Research Foundation) SFB 854 (A04), 97850925 to $\mathrm{MN}$.

Availability of data and material All data generated and analyzed during the current study are included in this published article and its additional files.

Code availability Not applicable.

\section{Declarations}

Conflict of interest The authors declare that they have no competing interests.

Ethics approval Ethik-Kommission der Friedrich-Alexander-Universität Erlangen-Nürnberg, Krankenhausstr. 12, 91054 Erlangen (Antrag Nr. 34720 Bc).

Consent to participate Not applicable.

Consent for publication All the authors have approved and agreed to publish this manuscript.

Open Access This article is licensed under a Creative Commons Attribution 4.0 International License, which permits use, sharing, adaptation, distribution and reproduction in any medium or format, as long as you give appropriate credit to the original author(s) and the source, provide a link to the Creative Commons licence, and indicate if changes were made. The images or other third party material in this article are included in the article's Creative Commons licence, unless indicated otherwise in a credit line to the material. If material is not included in the article's Creative Commons licence and your intended use is not permitted by statutory regulation or exceeds the permitted use, you will need to obtain permission directly from the copyright holder. To view a copy of this licence, visit http://creativecommons.org/licenses/by/4.0/.

\section{References}

1. Zamani M, Ebrahimtabar F, Zamani V, Miller WH, AlizadehNavaei R, Shokri-Shirvani J et al (2018) Systematic review with meta-analysis: the worldwide prevalence of Helicobacter pylori infection. Aliment Pharmacol Ther 47(7):868-876. https://doi. org/10.1111/apt.14561

2. Park JY, Forman D, Waskito LA, Yamaoka Y, Crabtree JE (2018) Epidemiology of Helicobacter pylori and CagA-positive infections and global variations in gastric cancer. Toxins (Basel) 10(4):163. https://doi.org/10.3390/toxins 10040163

3. Chaithongyot S, Jantaree P, Sokolova O, Naumann M (2021) $\mathrm{NF}-\kappa \mathrm{B}$ in gastric cancer development and therapy. Biomedicines 9(8):870. https://doi.org/10.3390/biomedicines9080870

4. Taniguchi K, Karin M (2018) NF- $\kappa B$, inflammation, immunity and cancer: coming of age. Nat Rev Immunol 18:309-324. https://doi.org/10.1038/nri.2017.142

5. Neumann M, Naumann M (2007) Beyond IкBs: alternative regulation of NF- $\kappa$ B activity. FASEB J 21(11):2642-2654. https:// doi.org/10.1096/fj.06-7615rev

6. Neish AS, Naumann M (2011) Microbial-induced immunomodulation by targeting the NF- $\mathrm{KB}$ system. Trends Microbiol 19(12):596-605. https://doi.org/10.1016/j.tim.2011.08.004

7. Sun S-C (2017) The non-canonical NF-кB pathway in immunity and inflammation. Nat Rev Immunol 17:545-558. https://doi.org/ 10.1038/nri.2017.52

8. Maubach G, Feige MH, Lim MCC, Naumann M (2019) NF-кBinducing kinase in cancer. Biochim Biophys Acta (BBA)- Rev Cancer 1871(1):40-49. https://doi.org/10.1016/j.bbcan.2018.10. 002

9. Sanjo H, Zajonc DM, Braden R, Norris PS, Ware CF (2010) Allosteric regulation of the ubiquitin:NIK and ubiquitin:TRAF3 E3 ligases by the lymphotoxin- $\beta$ receptor. J Biol Chem 285(22):17148-17155. https://doi.org/10.1074/jbc.M110.105874

10. Vallabhapurapu S, Matsuzawa A, Zhang W, Tseng P-H, Keats JJ, Wang $\mathrm{H}$ et al (2008) Nonredundant and complementary functions of TRAF2 and TRAF3 in a ubiquitination cascade that activates NIK-dependent alternative NF- $\kappa$ B signaling. Nat Immunol 9:1364-1370. https://doi.org/10.1038/ni.1678

11. Fusco AJ, Mazumder A, Wang VY-F, Tao Z, Ware C, Ghosh G (2016) The NF-kB subunit RelB controls p100 processing by competing with the kinases NIK and IKK1 for binding to p100. Science Signaling 9(447):ra96-ra96. https://doi.org/10.1126/scisi gnal.aad9413

12. Bren GD, Solan NJ, Miyoshi H, Pennington KN, Pobst LJ, Paya CV (2001) Transcription of the RelB gene is regulated by NF- $\kappa$ B . Oncogene 20(53):7722-7733. https://doi.org/10.1038/sj.onc. 1204868

13. Lombardi L, Ciana P, Cappellini C, Trecca D, Guerrini L, Migliazza A et al (1995) Structural and functional characterization of the promoter regions of the NFKB2 gene. Nucleic Acids Res 23(12):2328-2336. https://doi.org/10.1093/nar/23.12.2328

14. Sokolova O, Borgmann M, Rieke C, Schweitzer K, Rothkotter HJ, Naumann M (2013) Helicobacter pylori induces type 4 secretion system-dependent, but CagA-independent activation of IkappaBs and NF- $\mathrm{kB} / \mathrm{RelA}$ at early time points. Int J Med Microbiol 303(8):548-552. https://doi.org/10.1016/j.ijmm.2013.07.008

15. Schweitzer K, Sokolova O, Bozko PM, Naumann M (2010) Helicobacter pylori induces NF- $\kappa$ B independent of CagA. EMBO Rep 11(1):10-11. https://doi.org/10.1038/embor.2009.263

16. Zhou P, She Y, Dong N, Li P, He H, Borio A et al (2018) Alphakinase 1 is a cytosolic innate immune receptor for bacterial ADP-heptose. Nature 561:122-126. https://doi.org/10.1038/ s41586-018-0433-3

17. Milivojevic M, Dangeard A-S, Kasper CA, Tschon T, Emmenlauer M, Pique $C$ et al (2017) ALPK1 controls TIFA/TRAF6-dependent innate immunity against heptose-1,7-bisphosphate of gram-negative bacteria. PLoS Pathog 13(2):e1006224. https://doi.org/10. 1371/journal.ppat.1006224 
18. Maubach G, Lim MCC, Sokolova O, Backert S, Meyer TF, Naumann M (2021) TIFA has dual functions in Helicobacter pyloriinduced classical and alternative NF- $\mathrm{KB}$ pathways. EMBO Rep 22(9):e52878. https://doi.org/10.15252/embr.202152878

19. Martens A, van Loo G (2019) A20 at the crossroads of cell death, inflammation, and autoimmunity. Cold Spring Harb Perspect Biol. https://doi.org/10.1101/cshperspect.a036418

20. Wertz IE, Newton K, Seshasayee D, Kusam S, Lam C, Zhang $\mathrm{J}$ et al (2015) Phosphorylation and linear ubiquitin direct A20 inhibition of inflammation. Nature 528(7582):370-375. https:// doi.org/10.1038/nature16165

21. Skaug B, Chen J, Du F, He J, Ma A, Chen Zhijian J (2011) Direct, noncatalytic mechanism of IKK inhibition by A20. Mol Cell 44(4):559-571. https://doi.org/10.1016/j.molcel.2011.09.015

22. Verhelst K, Carpentier I, Kreike M, Meloni L, Verstrepen L, Kensche $\mathrm{T}$ et al (2012) A20 inhibits LUBAC-mediated NF- $\mathrm{\kappa B}$ activation by binding linear polyubiquitin chains via its zinc finger 7 . EMBO J 31(19):3845-3855. https://doi.org/10.1038/emboj.2012. 240

23. Bosanac I, Wertz IE, Pan B, Yu C, Kusam S, Lam C et al (2010) Ubiquitin binding to $\mathrm{A} 20 \mathrm{ZnF} 4$ is required for modulation of NF-кB signaling. Mol Cell 40(4):548-557. https://doi.org/10. 1016/j.molcel.2010.10.009

24. Tokunaga F, Nishimasu H, Ishitani R, Goto E, Noguchi T, Mio $\mathrm{K}$ et al (2012) Specific recognition of linear polyubiquitin by A20 zinc finger 7 is involved in NF- $\mathrm{KB}$ regulation. EMBO J 31(19):3856-3870. https://doi.org/10.1038/emboj.2012.241

25. Bartfeld S, Bayram T, van de Wetering M, Huch M, Begthel H, Kujala P et al (2015) In vitro expansion of human gastric epithelial stem cells and their responses to bacterial infection. Gastroenterology 148(1):126-136.e126. https://doi.org/10.1053/j.gastro. 2014.09.042

26. Boccellato F, Woelffling S, Imai-Matsushima A, Sanchez G, Goosmann C, Schmid M et al (2019) Polarised epithelial monolayers of the gastric mucosa reveal insights into mucosal homeostasis and defence against infection. Gut 68(3):400-413. https:// doi.org/10.1136/gutjnl-2017-314540

27. Schlaermann P, Toelle B, Berger H, Schmidt SC, Glanemann M, Ordemann J et al (2016) A novel human gastric primary cell culture system for modelling Helicobacter pylori infection in vitro. Gut 65(2):202-213. https://doi.org/10.1136/gutjnl-2014-307949

28. Sokolova O, Maubach G, Naumann M (2014) MEKK3 and TAK1 synergize to activate IKK complex in Helicobacter pylori infection. Biochim Biophys Acta (BBA) - Mol Cell Res 1843(4):715724. https://doi.org/10.1016/j.bbamcr.2014.01.006

29. Feige MH, Vieth M, Sokolova O, Täger C, Naumann M (2018) Helicobacter pylori induces direct activation of the lymphotoxin beta receptor and non-canonical nuclear factor- $\kappa$ B signaling. Biochim Biophys Acta (BBA)- Mol Cell Res 1865(4):545-550. https://doi.org/10.1016/j.bbamcr.2018.01.006

30. Yamaguchi N, Oyama M, Kozuka-Hata H, Inoue J (2013) Involvement of A20 in the molecular switch that activates the non-canonical NF-кB pathway. Sci Rep 3:2568. https://doi.org/10.1038/srep0 2568

31. de Oliveira KAP, Kaergel E, Heinig M, Fontaine J-F, Patone G, Muro EM et al (2016) A roadmap of constitutive NF- $\kappa B$ activity in Hodgkin lymphoma: dominant roles of p50 and p52 revealed by genome-wide analyses. Genome Med 8(1):28. https://doi.org/ 10.1186/s13073-016-0280-5
32. Ganeff C, Remouchamps C, Boutaffala L, Benezech C, Galopin $\mathrm{G}$, Vandepaer $\mathrm{S}$ et al (2011) Induction of the alternative NF- $\mathrm{KB}$ pathway by lymphotoxin $\alpha \beta(L T \alpha \beta)$ relies on internalization of LT $\beta$ receptor. Mol Cell Biol 31(21):4319-4334. https://doi.org/ 10.1128/mcb.05033-11

33. Sun S-C (2011) Non-canonical NF- $\kappa B$ signaling pathway. Cell Res 21:71-85. https://doi.org/10.1038/cr.2010.177

34. Madge LA, Kluger MS, Orange JS, May MJ (2008) Lymphotoxin$\alpha 1 \beta 2$ and LIGHT induce classical and noncanonical NF- $\kappa \mathrm{B}-$ dependent proinflammatory gene expression in vascular endothelial cells. J Immunol 180(5):3467-3477. https://doi.org/10.4049/ jimmunol.180.5.3467

35. Lau TS, Chung TK, Cheung TH, Chan LK, Cheung LW, Yim SF et al (2014) Cancer cell-derived lymphotoxin mediates reciprocal tumour-stromal interactions in human ovarian cancer by inducing CXCL11 in fibroblasts. J Pathol 232(1):43-56. https://doi.org/10. 1002/path.4258

36. Mikami Y, Matsuzaki H, Horie M, Noguchi S, Jo T, Narumoto $\mathrm{O}$ et al (2014) Lymphotoxin $\beta$ receptor signaling induces IL-8 production in human bronchial epithelial cells. PLoS One 9(12):e114791. https://doi.org/10.1371/journal.pone.0114791

37. Macho-Fernandez E, Koroleva EP, Spencer CM, Tighe M, Torrado E, Cooper AM et al (2015) Lymphotoxin beta receptor signaling limits mucosal damage through driving IL-23 production by epithelial cells. Mucosal Immunol 8(2):403-413. https://doi.org/ 10.1038/mi.2014.78

38. Wang Y, Koroleva EP, Kruglov AA, Kuprash DV, Nedospasov SA, $\mathrm{Fu} Y-X$ et al (2010) Lymphotoxin $\beta$ receptor signaling in intestinal epithelial cells orchestrates innate immune responses against mucosal bacterial infection. Immunity 32(3):403-413. https://doi. org/10.1016/j.immuni.2010.02.011

39. Lim MCC, Maubach G, Sokolova O, Feige MH, Diezko R, Buchbinder J et al (2017) Pathogen-induced ubiquitin-editing enzyme A20 bifunctionally shuts off NF- $\mathrm{KB}$ and caspase-8-dependent apoptotic cell death. Cell Death Differ 24(9):1621-1631. https:// doi.org/10.1038/cdd.2017.89

40. Brandl M, Seidler B, Haller F, Adamski J, Schmid RM, Saur D et al (2010) IKK $\alpha$ controls canonical TGF $\beta$-SMAD signaling to regulate genes expressing SNAIL and SLUG during EMT in Panc1 cells. J Cell Sci 123(24):4231-4239. https://doi.org/10. $1242 /$ jcs. 071100

41. Studencka-Turski M, Maubach G, Feige MH, Naumann M (2018) Constitutive activation of nuclear factor $\mathrm{\kappa B}$-inducing kinase counteracts apoptosis in cells with rearranged mixed lineage leukemia gene. Leukemia 32(11):2498-2501. https://doi.org/10.1038/ s41375-018-0128-7

42. Remmele W, Stegner HE (1987) Recommendation for uniform definition of an immunoreactive score (IRS) for immunohistochemical estrogen receptor detection (ER-ICA) in breast cancer tissue. Pathologe 8(3):138-140

43. Schneider CA, Rasband WS, Eliceiri KW (2012) NIH Image to ImageJ: 25 years of image analysis. Nat Meth 9(7):671-675. https://doi.org/10.1038/nmeth.2089

Publisher's Note Springer Nature remains neutral with regard to jurisdictional claims in published maps and institutional affiliations. 